\title{
Uso de geotecnologias para identificação de ilhas de calor no município de Belém (PA)
}

O meio ambiente e a qualidade de vida nas cidades têm sido alterados com a urbanização, provocando vários problemas nas condições do clima local. Um dos mais comuns é a llha de Calor (IC). Dessa maneira, o presente estudo teve como finalidade investigar a presença de llhas de Calor em pontos turísticos da cidade de Belém (PA). Para as análises, definiram-se 38 pontos, sendo 19 na área urbana e 19 na rural. Os dados de temperatura foram obtidos através do Google Earth Engine, utilizando o produto do sensor MODIS/MOD11A2, no período de 2012 a 2016 . Os resultados indicam que há diferença de cerca de $5^{\circ} \mathrm{C}$ em média das temperaturas do dia e da noite, sendo que a temperatura do dia se apresentava mais intensa que a da noite, tanto na zona urbana, quanto na rural. As IC na cidade de Belém apresentaram temperatura média de $33^{\circ} \mathrm{C}$. A diferença da média dos pontos urbanos para os rurais é de aproximadamente $6^{\circ} \mathrm{C}$. O uso dos dados do GEE demonstrou muita eficácia e rapidez nas análises, principalmente em relação ao processamento direto na plataforma fato que contribui na redução significativa do tempo de análise no SIG. Diante do exposto, verificou-se que o diagnóstico das ilhas de calor se apresentou como uma ferramenta de auxílio para a gestão do ambiente urbano, demonstrando a necessidade de intervenção do poder público nas áreas que estão sofrendo com a presença desse fenômeno.

\section{Use of geotechnologies for identification of heat islands in the municipality of Belém (PA)}

\begin{abstract}
The environment and quality of life in cities have been altered with urbanization, causing various problems in local climate conditions. One of the most common is the Heat Island (IC). Thus, the present study aimed to investigate the presence of Heat Islands in tourist spots of the city of Belém (PA). For the analyzes, 38 points were defined, 19 in the urban area and 19 in the rural area. Temperature data were obtained from Google Earth Engine using the MODIS / MOD11A2 sensor product from 2012 to 2016 . Results indicate that there is a difference of about $5^{\circ} \mathrm{C}$ on average day and night temperatures, the temperature of the day was more intense than the night, both in urban and rural areas. The $\mathrm{Cls}$ in the city of Belém had an average temperature of $33^{\circ} \mathrm{C}$. The difference in average from urban to rural points is approximately $6^{\circ} \mathrm{C}$. The use of GHG data demonstrated very efficient and fast analysis, especially in relation to direct processing in the platform which contributes to a significant reduction in GIS analysis time. Given the above, it was found that the diagnosis of heat islands was presented as an aid tool for the management of the urban environment, demonstrating the need for public intervention in areas suffering from the presence of this phenomenon.
\end{abstract}

Keywords: Multitemporal; Remote sensing; Google Earth Engine; Temperature.

Topic: Desenvolvimento, Sustentabilidade e Meio Ambiente

Reviewed anonymously in the process of blind peer

Karla de Santos

Universidade do Estado do Pará, Brasil

http://lattes.cnpq.br/9074284073523057

karla.pehse@gmail.com

Ricardo José de Paula Souza e Guimarães (iD

Instituto Evandro Chagas, Brasil

http://lattes.cnpq.br/4082971128842907

http://orcid.org/0000-0002-5767-4765

ricardojpsg@gmail.com

Brenda Caroline Sampaio da Silva

Faculdade Estácio de Belém, Brasil

http://lattes.cnpq.br/5425559156577411

brendacaroline444@gmail.com
Received: 09/10/2018

Approved: 09/11/2018
Altem Nascimento Pontes (iD)

Universidade do Estado do Pará, Brasil

http://lattes.cnpq.br/5993352890364998

http://orcid.org/0000-0002-9001-4603

altempontes@hotmail.com

Gundisalvo Piratoba Morales

Universidade do Estado do Pará, Brasil

http://lattes.cnpq.br/2923392000120182

gundymorales@gmail.com
Referencing this:

SANTOS, K.; GUIMARÃES, R. J. P. S.; SILVA, B. C. S.; PONTES, A. N.; MORALES, G. P.. Uso de geotecnologias para identificação de ilhas de calor no município de Belém (PA). Revista Ibero-Americana de Ciências Ambientais, v.9, n.8, p.178-186, 2019. DOI: http://doi.org/10.6008/CBPC2179-6858.2018.008.0016

DOI: $10.6008 / C B P C 2179-6858.2018 .008 .0016$ 


\section{INTRODUÇÃO}

A partir dos séculos XIX e XX surgiu uma nova revolução urbana que gerou imensas transformações sociais, criando dessa maneira sociedades "metropolizadas" (LOPES, 2008). Dessa forma, a crescente urbanização colaborou para grande melhoria na vida da população, principalmente em relação ao crescimento da geração de emprego e renda dessas regiões (FRANÇA et al., 2015). Para Lopes (2008) e França et al. (2015), com o passar do tempo, essa melhoria tem provocado impactos negativos.

No Brasil, as alterações no cotidiano rural, especialmente a modificação das atividades de sustento para grandes culturas, foram responsáveis pelo êxodo rural a partir da década de 50, o que contribuiu para a transferência da população do meio rural para o urbano, colaborando assim para a geração de grandes centros urbanos no País (GROSTEIN, 2001). Deste modo, as cidades brasileiras, que possuem vastos atrativos econômicos, dispõem de um modelo de crescimento relativamente insustentável (MACHADO et al., 2012). E ainda, conforme Lehoczky et al. (2017), os centros urbanos se encontram como "hotspots" das modificações das variáveis climáticas, influenciando no clima em razão do crescimento urbano acelerado e do intenso calor que, quando aliados, podem causar grandes impactos sociais, econômicos e ambientais.

Conforme Schmitz et al. (2011), o meio ambiente e a qualidade de vida nas cidades têm sido alterados com a urbanização, por meio da impermeabilidade do solo, emissão de poluentes, supressão vegetal, crescimento da frota de veículos e outros, provocando mudanças nas condições do clima local. Para Santana (2014), nas metrópoles são gerados diversos problemas relacionados ao clima, um dos mais comuns são as Ilhas de Calor (IC).

De acordo com a United States Environmental Protection Agency e Roth (2007), as IC são definidas como o aquecimento das áreas urbanas em relação às áreas rurais, sendo causadas pela transformação exorbitante do meio natural, com áreas verdes limitadas e impermeabilização dos solos com materiais de baixo albedo. Segundo Gartland (2010), o fenômeno da IC vem sendo observado em cidades em todo o mundo. O primeiro estudo de calor urbano ocorreu em 1818, realizado por Luke Howard, que efetuou análises sobre o clima de Londres e detectou altos índices de calor artificial na cidade, em relação ao campo (HOWARD, 1833).

O sensoriamento remoto tem sido de grande aplicabilidade nos estudos e pesquisas relacionadas ao meio ambiente, demonstrando grande crescimento do uso de suas ferramentas na área científica (BARBOSA et al., 2007). Para Barbosa et al. (2007), os dados de infravermelho termal capturados pelo sensoriamento remoto proporcionam a análise do comportamento térmico e o estudo de anomalias térmicas.

O uso do sensoriamento remoto na análise termal permite a identificação da temperatura de superfície dependendo da disponibilidade de imagens para os períodos analisados, detectando mudanças e alterações no fenômeno temperatura ao longo da superfície analisada (TSUYUGUCHI et al., 2010). Lazarim et al. (2011) salienta que as principais vantagens do sensoriamento remoto são a geração de parâmetros físicos da superfície terrestre a partir de um montante quase contínuo de informações com alta resolução 
temporal e espacial, juntamente com a possibilidade de obtenção de subsídios detalhados para regiões de grandes dimensões em um tempo razoavelmente curto.

Atualmente, muitos estudos têm sido realizados para estudar as IC. Gallo et al. (1993) utilizou dados do sensor AVHRR (Advanced Very High Resolution Radiometer) do satélite NOAA (National Oceanic Atmospheric Administration) para determinar diferenças urbanas/rurais na temperatura da superfície em 37 cidades dos EUA. Já Xie et al. (2005), para estudar o fenômeno da IC em San Antônio, Texas, usaram o produto de temperatura MODIS / Aqua (PM satélite) (MYD11A1, diário e 1km de resolução espacial), do período de

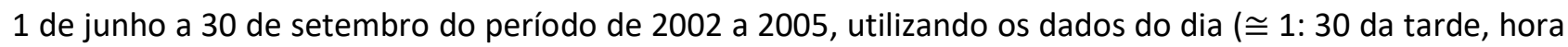
padrão central - CST) e da noite (1: 30 da manhã, CST). A existência de uma IC no centro de San Antônio foi claramente mostrada em $\cong 90 \%$ dos dados disponíveis sem nuvens. As nuvens prevaleceram mais nas imagens noturnas do que nas imagens diurnas. O estudo das IC, através da análise da temperatura em locais que existam determinadas atividades econômicas, constitui-se como uma oportunidade de demonstrar como os efeitos da urbanização podem ser prejudiciais.

Para a sociedade brasileira e mundial, o turismo se estabelece como uma oportunidade de se promover a atividade econômica local resultando na geração de empregos para a população e renda para o município ou estados em questão (DIAS et al., 2003). Para Dias et al. (2003), o turismo se apresenta como uma atividade variada que se interliga a inúmeros elementos econômicos e necessita de um agrupamento de atuações setoriais para o seu progresso, constituindo-se uma atividade modificadora do espaço. Em vista disto, o município de Belém dispõe de uma enorme variedade de produtos turísticos que atraem e encantam turistas de todo o mundo (PARATUR, 2009). Dessa maneira, o objetivo do presente estudo foi empregar as geotecnologias na identificação de IC em pontos turísticos da cidade de Belém, Pará.

\section{METODOLOGIA}

\section{Área de estudo}

O estudo foi realizado no município de Belém, capital do estado do Pará, que se situa a 22 metros de altitude, e possui as seguintes coordenadas geográficas: Latitude: $1^{\circ} 27^{\prime} 18^{\prime \prime}$ Sul, Longitude: $48^{\circ} 30^{\prime} 9^{\prime \prime}$ Oeste. Belém possui uma população estimada de 1.446 .042 habitantes e uma área territorial de $1.059,458 \mathrm{~km}^{2}$. A figura 1 apresenta o mapa de localização de Belém.

\section{Pontos de turísticos}

Os pontos turísticos para esse estudo foram escolhidos utilizando como base o site da secretaria de turismo de Belém. As coordenadas dos pontos turísticos foram obtidas utilizando o software Google Earth. No total, foram selecionados 38 pontos, sendo 19 na área urbana e 19 na rural. Os pontos da área urbana foram coletados em 11 bairros do centro de Belém e os pontos da área rural foram coletados em quatro ilhas e no distrito de Icoaraci, conforme indica a figura 1. 


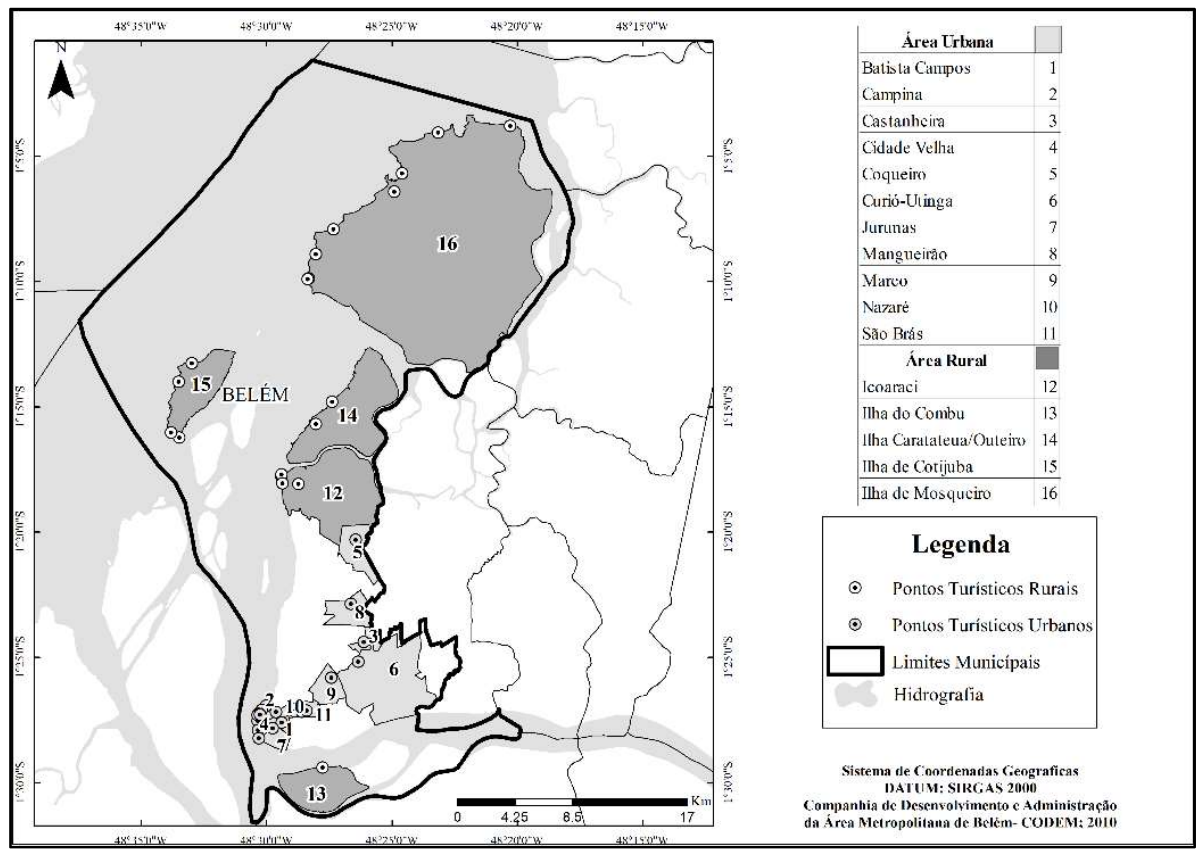

Figura 1: Mapa de localização da área de estudo, determinada como urbana e rural.

O quadro 1 resume as informações dos pontos turísticos de Belém (PA). O período de estudo foi de 2012 a 2016, entretanto, não foi possível realizar a análise mensal devido, nos primeiros meses, a presença de nuvens que impossibilita obter a temperatura. Dessa maneira, analisou-se o período de agosto a novembro, que segundo Rodrigues et al. (2011), representa o período menos chuvoso na região amazônica.

Quadro 1: Descrição dos pontos turísticos de Belém (PA).

\begin{tabular}{|c|c|c|c|}
\hline \multicolumn{2}{|l|}{ URBANO } & \multicolumn{2}{|l|}{ RURAL } \\
\hline PONTOS TURISTICOS & BAIRRO & PONTOS TURISTICOS & LOCAIS \\
\hline $\begin{array}{ll}1 & \text { Estacao das Docas } \\
2 & \text { Teatro da Paz/Praça da Repulblica }\end{array}$ & Campina & \multirow{3}{*}{$\begin{array}{l}20 \text { Nossa Senhora do Ó } \\
21 \text { Mercado Municipal } \\
22 \text { Chapeu Virado } \\
23 \text { Praia Baia do Sol } \\
24 \text { Praia grande } \\
25 \text { Praça Carananduba } \\
26 \text { Praia do Paraíso } \\
27 \text { São Francisco } \\
\end{array}$} & \multirow[b]{3}{*}{$\begin{array}{c}\text { Ilha de } \\
\text { Mosqueiro }\end{array}$} \\
\hline 3 Praça Batista Campos & Batista Campos & & \\
\hline $\begin{array}{ll}4 & \text { Ver-o-peso } \\
5 & \text { Catedral da Sé } \\
6 & \text { Igreja Nossa Senhora do Carmo } \\
7 & \text { Mangal das Garças } \\
8 & \text { Forte do Presépio }\end{array}$ & \multirow[t]{2}{*}{ Cidade Velha } & & \\
\hline 9 Museu da Arte Sacra & & 28 Escola Bosque & llha de \\
\hline 10 Memorial da Cabanagem & Castanheira & 29 Praia do Barro Branco & Outeiro \\
\hline 11 Parque dos Igarapes & Coqueiro & \multirow{3}{*}{$\begin{array}{l}30 \text { Ruínas do Antigo Educandario } \\
31 \text { Il ha do Farol } \\
32 \text { Praia vai-quem-quer } \\
33 \text { Praia da flexeira }\end{array}$} & \multirow{3}{*}{$\begin{array}{l}\text { llha de } \\
\text { Cotijuba }\end{array}$} \\
\hline 12 Parque Estadual do Utinga & Curió-Utinga & & \\
\hline $\begin{array}{l}13 \text { Pólo Joal heiro } \\
14 \text { Portal da Amazônia }\end{array}$ & Jurunas & & \\
\hline 15 Estadio Mangueirao & Mangueirão & \multirow{3}{*}{$\begin{array}{l}34 \text { Feira de artesanato } \\
35 \text { Orla de Icoaraci } \\
36 \text { Chale Tavares Cardoso } \\
37 \text { Cemiterio Santa Isabel }\end{array}$} & \multirow[b]{3}{*}{ Icoaraci } \\
\hline 16 Bosque Rodrigues Alves & Marco & & \\
\hline $\begin{array}{l}17 \text { Basilica de Nossa Senhora de } \\
\text { Nazaré } \\
18 \text { Museu Emilio Goeldi }\end{array}$ & Nazaré & & \\
\hline 19 Parque da Residência & São Brás & 38 Ilha do Combu & \\
\hline
\end{tabular}

Os dados de temperatura foram obtidos através do Google Earth Engine (GEE), utilizando o produto do sensor MODIS MOD11A2. O produto MOD11 compreende a coleção C5 de dados de emissividade e temperatura da superfície da Terra (dia e noite) em uma composição sem nuvens no período de 8 dias e com uma resolução espacial de $1 \mathrm{~km}$ (WAN et al., 2002).

GEE é uma plataforma baseada na nuvem de dados que reúne mais de 40 anos de imagens históricas e atuais de sensoriamento remoto. Todos os dados são pré-processados, georreferenciados e prontos para 
uso. O GEE combina um arquivo em escala petabyte de imagens acessíveis publicamente e outros dados, uma infraestrutura computacional otimizada para o processamento paralelo de dados geoespaciais, uma interface de programação de aplicativos (API) e um ambiente de desenvolvimento integrado (IDE) baseado na Web utilizando JavaScript e Python para a visualização de análises espaciais complexas.

\section{Processamento dos dados}

Os dados com o nome dos pontos turísticos e suas respectivas coordenadas foram importados para o GEE utilizando a função Fusion Tables. Os dados de temperatura do dia e da noite do produto MODIS11A2 foram obtidos usando um script que seleciona o sensor/banda de interesse, assim como o período de interesse (dia/mês/ano), retornando como resultado a temperatura em graus Celsius, conforme o modelo que segue proposto: var Istday = ee.ImageCollection('MODIS/MOD11A2').filterDate('2012-08-01', '2012-1130').select('LST_Day_1 $1 \mathrm{~km}$ ');:map(function(image)\{returnimage.multiply(0.02).subtract(273.15).set('system:t ime_start', image.get('system:time_start'));\});:

Os valores da temperatura do dia e da noite foram exportados para o formato CSV (commaseparated values) por ano. Os CSVs foram utilizados para gerar os gráficos e verificar as diferenças das temperaturas nas áreas rural e urbana e, dessa forma, verificar a possível existência de IC. Também, com auxílio do GEE, foram obtidas as imagens anuais de temperatura do dia e noite do mesmo período selecionado. Essas imagens foram importadas para um Sistema de Informações Geográficas (SIG), onde foram elaborados os mapas correspondentes de temperatura do período menos chuvoso dos anos estudados. Para isso, empregaram-se os softwares Excel para fazer os gráficos e o ArcGis para gerar os mapas.

\section{RESULTADOS}

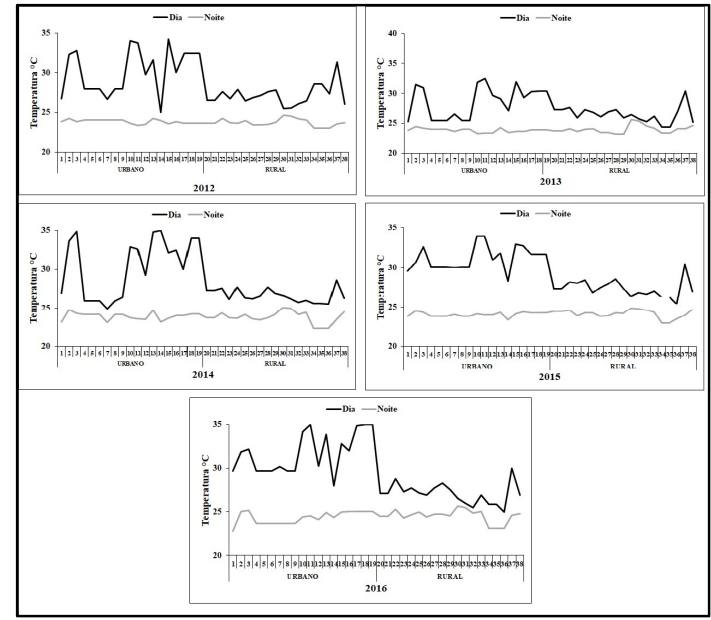

Figura 2: Gráficos da temperatura do dia e da noite dos pontos turísticos urbanos e rurais de 2012 a 2016 no município de Belém.

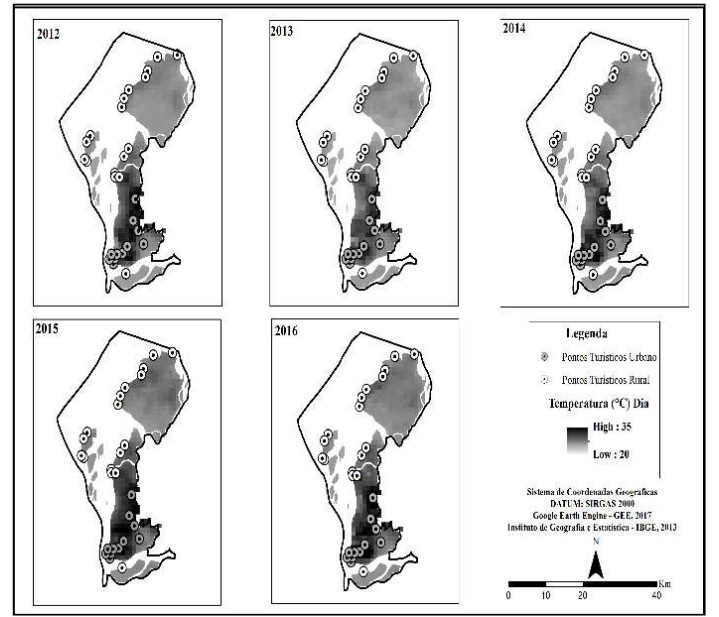

Figura 3: Mapa demonstrativo da temperatura média do dia no município de Belém.

A figura 2 mostra os gráficos de temperatura do dia e da noite nos 38 pontos de turismo de Belém no período de 2012 a 2016 obtidos utilizando o GEE. A figura 3 apresenta a temperatura média do dia, enquanto a Figura 4 exibe a temperatura média da noite. Ambas retratam as temperaturas do município de 
Belém, no período de estudo, apontando as áreas de maior intensidade de calor e os pontos turísticos que apresentaram maiores índices de temperatura. Com isso, foi possível a comparação das temperaturas médias do dia e da noite, viabilizando a identificação e melhor visualização das prováveis ilhas de calor existentes em pontos turísticos de Belém, Pará.

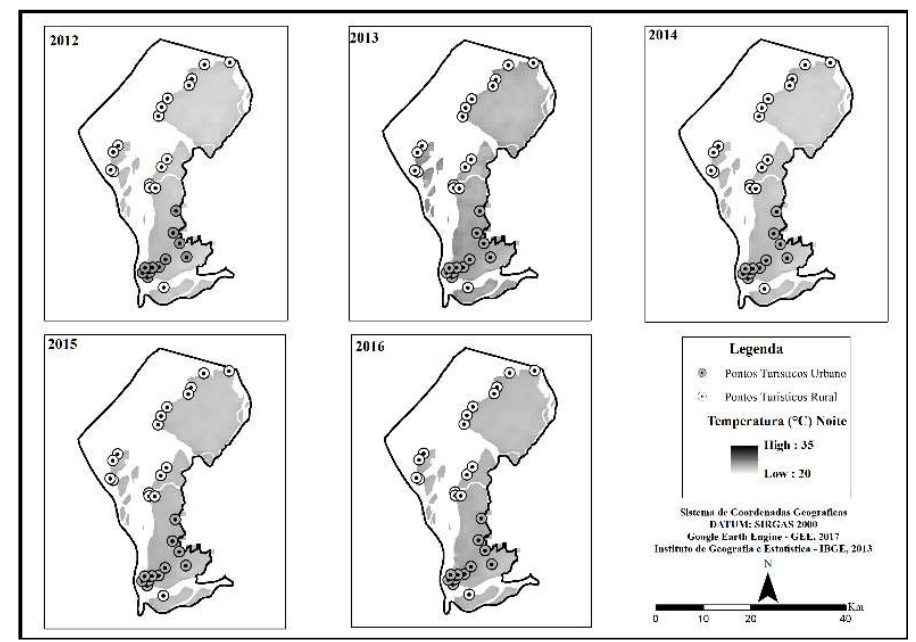

Figura 4: Mapa demonstrativo da temperatura média da noite no município de Belém.

\section{DISCUSSÃO}

A figura 2 mostra que existe uma diferença de cerca de $5^{\circ} \mathrm{C}$ em média das temperaturas do dia e da noite, sendo que a temperatura do dia se apresentava mais intensa que a da noite tanto na zona urbana (média de $30^{\circ} \mathrm{C}$ ) quanto na rural (média de $27^{\circ} \mathrm{C}$ ). Este fato pode estar atrelado à área urbana possuir mais solos impermeabilizados com edifícios e ruas pavimentadas, maior fluxo de carros, assim, o uso de materiais escuros nos edifícios e nos pavimentos colaboram para uma maior absorção de calor, dessa forma gerando uma temperatura maior, ou seja, uma IC (GARTLAND, 2010).

Os pontos referentes ao bairro da Cidade Velha apresentam temperaturas mais amenas em relação aos outros pontos turísticos urbanos principalmente o ponto do Mangal das Garças, entretanto tais locais estão próximos a Baía do Guajará e do Rio Guamá, desta forma, Oliveira et al. (2011) destacam que as áreas com existência de corpos hídricos possuem temperaturas mais amenas, haja vista que locais com ausência de corpos hídricos apresentam temperaturas superiores. Além disso, o Mangal das Garças possui áreas com vegetação.

Conforme Nicodemo (2009), as árvores urbanas contribuem na manutenção da umidade relativa do ar, através, da vaporização de água, assim, colaboram para que não haja elevação brusca da temperatura, atenuando as amplitudes térmicas, este fato foi observado também no Parque do Utinga, no bairro do CurióUtinga, que apresentou temperaturas inferiores aos demais pontos urbanos.

O único ponto averiguado no Bairro do Marco foi o Bosque Rodrigues Alves que apresenta grande arborização, mas sua temperatura se encontrou alta com relação aos pontos estudados, em todos os anos, isso se deve ao fato de o parque ser cercado por áreas impermeáveis onde à verticalização de edifícios é intensa aumentando a superfície de absorção de calor o que contribui para o aquecimento. Também, o Parque dos Igarapés possui intensa vegetação e sua temperatura se mostrou com altos índices, leva-se em 
consideração que o ponto analisado foi na entrada do parque, onde há pouca arborização. Segundo Modna et al. (2003), áreas pequenas com arborização, quando comparadas às demais áreas construídas seguem a tendência da temperatura mesoclimática.

A figura 2 mostra ainda que os pontos do Teatro da Paz/Praça da República, Praça Batista Campos, Memorial da Cabanagem, Estádio Mangueirão, Museu Emilio Geoldi e o Parque da residência, foram os pontos que apresentaram maiores índices de temperatura. Os pontos do Teatro da Paz/Praça da República e Praça Batista Campos dispõem de área arborizada, contudo são poucas árvores e estes possuem grande área impermeabilizada com muitas edificações e intenso trânsito de carros. Entretanto, conforme Zorzi (2016) os parques verdes urbanos limitados em área, não necessariamente influenciam no conforto térmico das cidades.

O ponto do Memorial da Cabanagem se situa em uma área aberta, com gramíneas, porém este está próximo à entrada de veículos de Belém no início da BR-316 com trânsito contínuo que possui um fluxo de veículos extremamente denso, com constantes congestionamentos, sendo que esta área apresenta ao seu redor edifícios e avenidas pavimentadas.

O ponto Estádio do Mangueirão se encontra em uma área sem qualquer vegetação e completamente impermeável, próximo à Avenida Augusto Montenegro de intenso trânsito de veículos, assim como nos pontos do Museu Emilio Goeldi e Parque da Residência, que fica de frente para a Av. Magalhães Barata. Apesar de possuir uma área vegetada, seus arredores são compostos por áreas impermeáveis com diversos condomínios verticais e uma área de intenso fluxo de veículos, dessa forma, segundo Alves et al. (2011), o desconforto térmico é mais nítido nos centros urbanos por apresentar uma circulação de veículos.

$\mathrm{Na}$ área rural, a temperatura se apresenta de maneira inferior à urbana. Verifica-se que somente o ponto do Cemitério Santa Isabel apresentou temperatura mais elevada em todos os anos, contudo o Cemitério se localiza bem no centro do distrito de Icoaraci, onde já se nota grande área urbanizada e o mesmo não apresenta nenhum tipo de vegetação em sua área. O distrito de Icoaraci não está situado em uma ilha como já mencionado anteriormente, porém o mesmo se encontra no limite das áreas mais urbanizadas para as rurais e ele serve como um indicador de urbanização da área de estudo.

As figuras 2 e 3 mostraram que a área urbana possui temperatura superior a área rural de Belém nos anos analisados. É possível visualizar através dos mapas que ao passar dos anos a temperatura nas áreas rurais aumentou gradativamente; isto pode ser em decorrência do aumento populacional nessa área. 0 crescimento da população gera a necessidade da alteração do ambiente natural por ambientes artificiais, isto tem contribuído intensamente nos altos índices de temperatura, segundo Moreira et al. (2009). O ano de 2015 foi o que apresentou maiores temperaturas nas áreas rural e urbana. Este fato pode estar atrelado à ocorrência do fenômeno do El niño, onde Grimm et al. (2015) afirmam que a ocorrência deste fenômeno em 2015 colaborou para altas temperaturas, gerando intensa seca no Norte e Nordeste do Brasil.

A partir da análise dos mapas da temperatura média da noite (Figura 4), nota-se que há pouca diferença visual da temperatura nos anos analisados, sendo que apenas o ano de 2013 apresenta temperatura mais elevada nas áreas costeira (rural). Entretanto, segundo Barbosa et al. (2014), o calor 
absorvido pela radiação do dia é dissipado sobretudo à noite, fazendo com que a temperatura se conserve alta. Verifica-se também que, ao longo dos anos, a temperatura noturna tem aumentado, sendo mais evidente a partir de 2014 no centro de Belém. Porém, esse aumento de temperatura ainda é bastante inferior quando se leva em consideração a temperatura do dia. Assim, Silva et al., (2016) ressaltam que uma das características das IC é a mudança no balanço total de radiação em relação a área urbana e a rural, em especial o aumento do índice de resfriamento ao longo da noite.

Diante das análises realizadas, notou-se que há a presença de IC em áreas que apresentam pontos turísticos, principalmente no Teatro da Paz/Praça da República, Praça Batista Campos, Memorial da Cabanagem, Estádio Mangueirão, Museu Emilio Goeldi e Parque da residência. Estes apresentam cobertura vegetal diferentes, todavia dispõem de características similares como grande fluxo de veículos, áreas próximas ou locais impermeabilizados, com vastas áreas edificadas.

Além disso, a diferença da área urbana para a rural é explicitamente nítida, levando em consideração Barros et al. (2016), onde afirma que a definição de IC urbana é estabelecida pelas disparidades das temperaturas dos centros urbanos em comparação à periferia ou a área rural. A média das temperaturas dos pontos com maior índice de temperatura foi de $33^{\circ} \mathrm{C}$, a diferença da média dos pontos rurais é de aproximadamente $6^{\circ} \mathrm{C}$, e assim se pode afirmar a partir desta diferença que há IC nestes locais.

\section{CONCLUSÃO}

A aplicação das geotecnologias na identificação de ilhas de calor em pontos turísticos da cidade de Belém se demonstrou muito eficiente, principalmente com o emprego do uso dos dados do GEE, que apresentam alta eficácia e grande rapidez nas análises, sobretudo, no fato de que não há necessidade de baixar todas as imagens do período de estudo para poder realizar o processamento dos dados, sendo que todo esse processamento é realizado pelos computadores do GEE e somente a resposta (área de interesse) retorna para o usuário.

Assim, o diagnóstico das IC mostrou-se como uma ferramenta de auxílio para a gestão do ambiente urbano, demonstrando a necessidade de intervenção do poder público nas áreas que estão sofrendo com a presença desse fenômeno, levando em consideração que as análises foram realizadas em pontos turísticos o que leva a um grande desconforto dos que procuram por estes pontos, evidenciando a carência de atenção com esses locais, pois são áreas em que há grande procura e que gera renda ao município. Recomenda-se aplicar a mesma metodologia em áreas onde a interferência de nuvens é menor, desse modo poderá obter uma comparação sazonal do fenômeno das ilhas de calor.

\section{REFERÊNCIAS}

ALVES, A.; ALVES, M. M. S.; AMARAL, A. L. M.; MORAIS, R. P.. Dinâmica do crescimento urbano e padrões de ocupação do solo na formação de microclimas urbanos na cidade de Anápolis-GO. In: SEMINÁRIO DE PIBIC E V SEMINÁRIO DE EXTENSÃO, 9. Anais. Anápolis: 2011.

BARBOSA, G. S.; ROSSI, A. M. G.; DRACH, P. R. C.. Análise de Projeto Urbano a partir de parâmetros urbanos sustentáveis: alteração morfológica de Copacabana e algumas de suas consequências climáticas (1930-1950-2010). Revista Brasileira de Gestão Urbana, Curitiba, v.6, n.3, 2014. DOI: http://doi.org/10.7213/urbe.06.003.AC01

BARBOSA, R. V.; VECCHIA, F. A. S.. Estudos de ilha de calor urbana por meio de imagens do Landsat7ETM+: estudo de 
caso em São Carlos (SP). Revista Pesquisa e Tecnologia Minerva, v.6, n.3, p.273-278, 2007.

BARROS, H. R.; LOMBARDO, M. A.. A ilha de calor urbana e o uso e cobertura do solo em São Paulo-SP. Geousp: Espaço e

Tempo, v.20, n.1, 2016. DOI:

https://doi.org/10.11606/issn.2179-

0892.geousp.2016.97783

DIAS, L. R.; MONTANHEIRO, R. B.. Turismo como fator de crescimento e desenvolvimento do município. Revista Turismo, 2003.

FRANÇA, L. M. A.; SANTOS, M. S.; LINS, T. M. P.; PEREIRA, J. A. S.; GALVÍNCIO, J. D.. Análise do desconforto térmico causado pela ilha de calor urbana em um bairro do Recife-PE utilizando sensoriamento remoto. SIMPÓSIO BRASILEIRO DE SENSORIAMENTO REMOTO, 17. Anais. João Pessoa: INPE, 2015.

GALLO, K. P.; MCNAB, A. L.; KARL, T. R.; BROWN, J. F.; HOOD, J. J.; TARPLEY, J. D.. The use of NOAA AVHRR data for assessment of the urban heat-island effect. International Journal of Remote Sensing, v.14, p.2223-2230, 1993. DOI: https://doi.org/10.1175/15200450(1993)032<0899:TUONAD $>2.0 . C 0 ; 2$

GARTLAND, L.. Ilhas de Calor: como mitigar zonas de calor com áreas urbanas. São Paulo: Oficina de Textos, 2010.

GRIMM, A. M.; ACEITUNO, P.. El niño, novamente. Revista Brasileira de Meteorologia, v.30, n.4, 2015. DOI: http://doi.org/10.1590/0102-778620152000

GROSTEIN, M. D.. Metrópole e expansão urbana: a persistência de processos 'insustentáveis'. São Paulo em Perspectiva, v.15, n.1, 2001. DOI: http://doi.org/10.1590/S0102-88392001000100003

HOWARD, L.. The climate of London Deduced from Meteorological Observations Made in the Metropolis and at Various Places around It. 2 ed. London: J. \& A. Arch, 1833.

LAZARIM, C. G.; ZULLO JUNIOR, J. Z.. Estimativa da temperatura da superfície terrestre, destinada ao monitoramento agrometeorológico de dias com temperaturas elevadas, utilizando dados do sensor AVHRR. In: SIMPÓSIO BRASILEIRO DE SENSORIAMENTO REMOTO, 15. Anais. São José dos Campos: INPE, 2011.

LEHOCZKY, A.; SOBRINO, J. A.; SKOKOVI'C, D.; AGUILAR, E. The urban heat island effect in the city of Valencia: a case study for hot summer days. Urban Science, v.1, n.9, 2017. DOI: https://doi.org/10.3390/urbansci1010009

LOPES, J. R. B.. Desenvolvimento e mudança social: formação da sociedade urbano-industrial no Brasil. Rio de Janeiro: Centro Edelstein de Pesquisas Sociais, 2008.

MACHADO, L. A.; CARMO, A. M. R.; JARDIM, C. H. Tendências e variações na temperatura e precipitação em Montes Claros e Sete Lagoas-MG. Revista Geonorte, v.2, n.5, 2012.
MODNA, D.; VECCHIA, F.. Calor e áreas verdes: um estudo preliminar do clima de São Carlos, SP. Curitiba: 2003.

MOREIRA, E. B. M.; GALVÍNCIO, J. D.. Análise multitempora da ilha de calor urbana na cidade do Recife, através de imagens do Landsat TM-5. In: SIMPÓSIO BRASILEIRO DE SENSORIAMENTO REMOTO, 14. Anais. Natal: INPE, 2009.

NICODEMO, M. L. F.. Por que manter árvores na área urbana?. São Carlos: Embrapa, 2009.

OLIVEIRA, D. E.; ASSIS, D. C.; FERREIRA, C. C. M.. A influência dos corpos hídricos na geração de microclimas urbanos: um estudo de caso da cidade de Juiz De Fora, MG. In: SIMPÓSIO BRASILEIRO DE GEOGRAFIA APLICADA, 14. Anais. Dourados: 2011.

PARATUR. Companhia Paraense de Turismo. Diagnóstico da Área e das Atividades Turísticas do Pólo Belém-PA. Belém: PARATUR, 2009

RODRIGUES, H. J. B.; SÁ, L. D. A.; RUIVO, M. L. P.; COSTA, A. C. L.; SILVA, R. B.; MOURA, Q. L.; MELLO, I. F.. Variabilidade quantitativa de população microbiana associada às condições microclimáticas observadas em solo de Floresta Tropical Úmida. Revista Brasileira de Meteorologia, v.26, n.4, 2011.

ROTH, M.. Review of urban climate research in (sub) tropica regions. International Journal of Climatology, v.27, 2007.

SANTANA, N. C.. Investigação de Ilhas de Calor em Brasília: Análise Multitemporal com Enfoque na Cobertura do Solo. Revista Brasileira de Geografia Física, v.7, n.6, 2014

SCHIMITZ, L. K.; MENDONÇA, F.. Reestruturação urbana e conforto térmico: cenários de modelização em Curitiba-PR após a copa de 2014. Revista Brasileira de Climatologia, v.8, n.7, 2011.

SILVA, I. A.; SANTOS, J. S.; VIEIRA, M. L. S.. Análise das ilhas de calor em um campus universitário no Litoral Norte da Paraíba. Revista de Geociências do Nordeste, v.2, 2016.

TSUYUGUCHI, B. B.; CUNHA, J. E. B. L.; RUFINO, I. A. A.. Uso De Geotecnologias Para Espacialização De Dados De Precipitação, Ndvi E Temperatura De Superfície Da Bacia Do Rio Taperoá. In: SIMPÓSIO BRASILEIRO DE CIÊNCIAS GEODÉSICAS E TECNOLOGIAS DA GEOINFORMAÇÃO, 3. Anais. Recife: 2010.

WAN, Z.; ZHANG, Y.; ZHANG, Q.; ZHAO-LIANG, L.. Validation of the land-surface temperature products retrieved from Terra Moderate Resolution Imaging Spectroradiometer data. Remote Sensing of Environment, v.83, 2002.

XIE, H.; GUAN, H.; YTUARTE, S.. Heat Island of San Antonio, Texas Detected By Modis: Aqua Temperature Product. In: BIENNIAL WORKSHOP ON AERIAL PHOTOGRAPHY VIDEOGRAPHY, AND HIGH RESOLUTION DIGITAL IMAGERY FOR RESOURCE ASSESSMENT, 20. Anais. Weslaco: 2005.

ZORZI, L. M.. A influência dos parques verdes no conforto térmico urbano: estudo de caso em Porto Alegre-RS. Porto Alegre: 2016.

A CBPC - Companhia Brasileira de Produção Científica (CNPJ: 11.221.422/0001-03) detém os direitos materiais desta publicação. Os direitos referem-se à publicação do trabalho em qualquer parte do mundo, incluindo os direitos às renovações, expansões e disseminações da contribuição, bem como outros direitos subsidiários. Todos os trabalhos publicados eletronicamente poderão posteriormente ser publicados em coletâneas impressas sob coordenação da Sustenere Publishing da Companhia Brasileira de Produção Científica e seus parceiros autorizados. Os (as) autores (as) preservam os direitos autorais, mas não têm permissão para a publicação da contribuição em outro meio, impresso ou digital, em português ou em tradução. 